\title{
Free Radicals in the Reaction of Alloxan with Glutathione and Ascorbic Acid *
}

\author{
CARL LAGERCRANTZ and MARGARETAYHLAND \\ Department of Medical Physics, University of Göteborg, Göteborg, Sweden
}

\begin{abstract}
With the technique of electron spin resonance (ESR) it has been found that free radicals are formed from alloxan by reduction with substances such as glutathione, cysteine and ascorbic acid. The reactions were studied in buffer solutions at room temperature. Radicals were detected in the $\mathrm{pH}$ interval between 4.6 and 8.6. The ESRspectra of the radicals exhibited a hyperfine structure consisting of seven equally spaced lines. An identical spectrum was obtained when dialuric acid was oxidized by potassium ferricyanide.

The origin of the seven-line spectra is suggested to be due to a combined interaction of the unpaired electron of the radicals with two equivalent ${ }^{14} \mathrm{~N}$ nuclei of the pyrimidine ring of alloxan, and with two equivalent imino protons. This interpretation is supported by the result obtained when the reaction leading to free radicals was performed in deuterium oxide. In this medium a five-line in place of the sevenline spectrum was observed, indicating an interaction of the odd electron with two ${ }^{14} \mathrm{~N}$ nuclei only after exchange of the imino protons for deuterium atoms.
\end{abstract}

Since Dunn et al. ${ }^{1}$ first described the diabetogenic properties of alloxan, much Sinterest has been displayed in the reaction mechanism of this substance. It was found that the prior injection of large doses of either glutathione or cysteine protected animals from the destructive lesions caused by alloxan in the $\beta$-cells of the islets of Langerhans in the pancreas. Further, it was found that the blood glutathione almost disappeared, and that the concentration of this substance in several tissues was considerably decreased after injection of alloxan ${ }^{2}$. Later studies in vitro showed that alloxan was reduced by glutathione to dialuric acid ${ }^{3}$. In view of these findings, Lazarow has postulated that the toxic effect of alloxan is produced by an inactivation of certain essential sulphydryl enzymes. The protective action of glutathione was believed to involve a reduction of alloxan to dialuric acid, a non-diabetogenic substance ${ }^{4}$. The selective sensitivity of the $\beta$-cells to alloxan was believed to depend on a

\footnotetext{
* A preliminary note on this work was submitted to Nordisk Biokemikermøde, København, January 1963.
}

Acta Chem. Scand. 17 (1963) No. 6 
low protective glutathione content due to a high consumption for the synthesis of insulin.

With the technique of electron spin resonance (FSR) it has been found that free radicals are formed in the reactions between alloxan and sulphydryl compounds, such as glutathione or cysteine, and ascorbic acid, respectively. These free radicals are very probably derived from alloxan by an one-electron reduction.

\section{METHODS AND MATERIALS}

The ESR-spectra were obtained with a Varian $100 \mathrm{kc}$ spectrometer. The experiments were performed with aqueous solutions at ambient room temperature. All ESRmeasurements were performed with the samples contained in a flat aqueous solution cell. Hyperfine splitting fields were measured by comparison with the splittings of a fresh solution of peroxylamine disulphonate (13.0 gauss). No measurements of g-values were made. In some of the experiments, degassing of the buffer solutions containing reducing substances was carried out prior to the addition of alloxan. The degassing procedure was performed by freezing, evacuating and melting with the sample contained in a small tube fitted to the sample cell. Solid alloxan was added before the final melting and the space above the solution and the solid alloxan was filled with nitrogen at atmospheric pressure.

Standard barbiturate and phosphate buffers were prepared with deaerated water. $\mathrm{pH}-$ measurements were made with a Radiometer, type PHM $3 \mathrm{~m} \mathrm{pH}$ meter. $\mathrm{pD}$ was measured with the same glass electrode, applying the correction factor of +0.40 units according to Glasoe and Long ${ }^{5}$.

Alloxan tetrahydrate (Merck), dialuric acid (Light and Co.), glutathione, reduced (Nutritional Biochem. Corp), cysteine hydrochloride (Merck), ascorbic acid (HoffmannLaRoche) and peroxylamine disulphonate (Aldrich) were used as supplied. Deuterium oxide $\left(\mathrm{D}_{2} \mathrm{O}\right)$ was delivered by Merck Sharp and Dohme of Canada Ltd.

\section{RESULTS}

$A$. Free radicals were obtained when alloxan was dissolved in phosphate or barbiturate buffers together with either glutathione, cysteine hydrochloride or ascorbic acid. No radicals could be detected in buffer solutions containing alloxan only, neither in degassed nor in non-degassed solutions, when the concentration of alloxan was $0.01 \mathrm{M}$ or lower. In a $0.1 \mathrm{M}$ solution of alloxan, however, radicals were present without any addition of glutathione, cysteine or ascorbic acid.

The experiments were performed as follows. To begin with, glutathione or one of the other reducing substances, was dissolved in the buffer solution. Solid alloxan was then added to the solution. The radical concentration was determined from an ESR-spectrum, recorded 5 min after the alloxan sample had been added. In these experiments no significant difference of the radical concentration could be observed between a non-degassed and a degassed solution. A comparison with a freshly prepared solution of peroxylamine disulphonate in water, showed a maximum of about $0.05 \%$ of the alloxan molecules to be free radicals.

When the substances were added and dissolved in the reverse order, i.e. alloxan first, the relative radical concentration was found to decrease with an increasing time interval between the addition of alloxan and glutathione. A comparison of the values obtained at a fixed time interval after the addition 


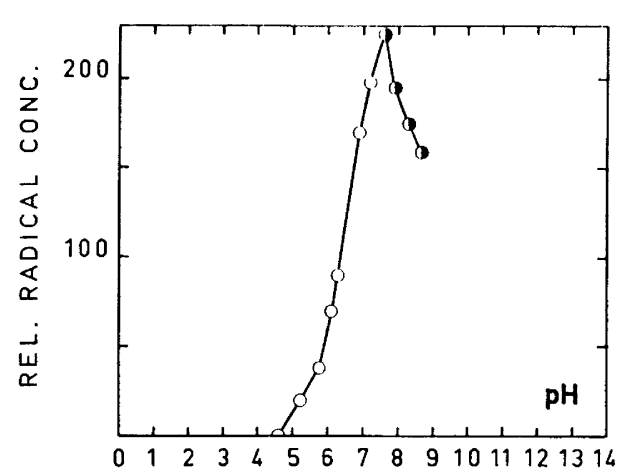

Fig. 1 . The relative yield of free radicals as a function of $\mathrm{pH}$ recorded 5 min after dissolving alloxan $(0.01 \mathrm{M})$ in a phosphate. $(\mathrm{O})$ or a barbiturate $(\Theta)$ buffer containing glutathione $(0.0075 \mathrm{M})$.

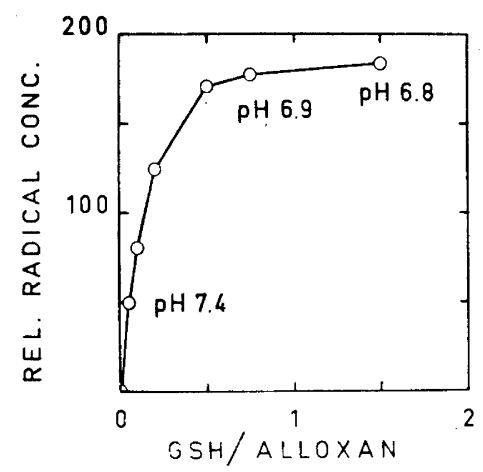

Fig. 2. The relative yield of free radicals as a function of the ratio alloxan to glutathione (GSH, $0.01 \mathrm{M}$ ) recorded 5 min after dissolving alloxan.

of glutathione showed that the radical concentration was lower in an alkaline than in a more acid medium. These findings seem to be consistent with the known instability of alloxan in neutral and alkaline media in which alloxan is transformed to alloxanic acid ${ }^{6}$. The decreased yield of radicals obtained with increasing time interval between the dissolution of alloxan and glutathione suggests that the presence of unchanged alloxan is necessary in order to get free radicals in these systems.

$B$. When the relative radical concentration was recorded $5 \mathrm{~min}$ after the addition of alloxan to the buffer-glutathione solution, the maximum yield was obtained at $\mathrm{pH} 7.6$ (Fig. 1). Radicals could be detected in the $\mathrm{pH}$ range between 4.6 and 8.6. These experiments were performed with a mole ratio between glutathione and alloxan equal to 0.75 . Since the acidity of the reaction mixtures increased when alloxan was converted to alloxanic acid, $\mathrm{pH}$ and radical concentration were both measured at the same time after the addition of
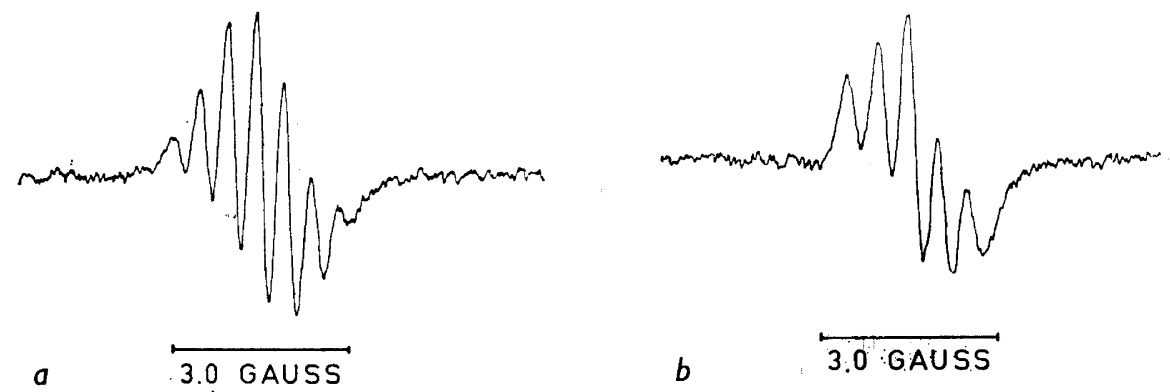

Fig. 3. ESR-spectrum of the free radicals from alloxan $(0.01 \mathrm{M})$ reduced by glutathione $(0.0075 \mathrm{M})$. Phosphate buffer. The first derivative of the absorption is recorded as a function of the magnetic field. a. in $\mathrm{H}_{2} \mathrm{O}, \mathrm{pH}$ 7.4; b. in $\mathrm{D}_{2} \mathrm{O}, \mathrm{pD}$ 7.2. 
alloxan. Both measurements were performed on samples taken from the same reaction mixture.

$C$. The radical concentration was found to increase with the glutathione concentration from zero to a nearly constant value which was attained when the mole ratio of glutathione to alloxan was about 0.75 to 1.0 . In order to compensate for the change of $\mathrm{pH}$ with increasing amounts of added glutathione, aliquots of $1 \mathrm{~N} \mathrm{NaOH}$ was added to the buffer-glutathione solutions prior to the addition of alloxan (Fig. 2).

$D$. The radical concentration decreased slowly with time. The decay was more rapid in an alkaline medium than in an acid one $(50 \%$ decomposition at $\mathrm{pH} 8.4$ in $6 \mathrm{~min}$, at $\mathrm{pH} 6.9$ in $18 \mathrm{~min}$ ). Due to the rather complicated behaviour of these systems in which both the starting material, i.e. alloxan, and the radicals are unstable, further kinetic studies were not carried out (see also Discussion).

$E$. When alloxan was added to fresh whole blood (heparinized) to make the concentration $0.01 \mathrm{M}$, sufficient amounts of reducing substances were present to produce radicals which could be identified by the hyperfine structure of the ESR-spectrum (see $F$.).

$F$. The ESR-spectra of the radicals exhibited a hyperfine structure consisting of seven equally spaced lines with a splitting field of about 0.4 gauss (Fig. 3a). The extreme width of the spectra was 3.0 gauss. The intensity ratio obtained by double integration was rather close to $1: 4: 8: 10: 8: 4: 1$. Identical spectra were obtained in the reactions of alloxan with either glutathione, cysteine hydrochloride or ascorbic acid. Also, the solutions of a higher alloxan concentration $(0.1 \mathrm{M}$, see $A$.) in which radicals were obtained without any addition of reducing substances exhibited ESR-spectra identical with those just described. Degassing of the solutions did not improve the resolution of the spectra.

When the reaction was performed in a buffer solution prepared from heavy water a five-line spectrum was obtained (Fig. 3b). The intensity distribution was rather close to $1: 2: 3: 2: 1$.

$G$. When dialuric acid $(0.02 \mathrm{M}, \mathrm{pH} 6.7)$ was oxidized by an equimolar amount of potassium ferricyanide, free radicals were formed which exhibited a spectrum identical with that obtained from alloxan.

\section{DISCUSSION}

Since identical ESR-spectra were obtained in the reactions described, the radicals are most likely derived from alloxan. The decreasing yield of radicals obtained with increasing time before the addition of glutathione to a solution containing alloxan as described in section $A$ seems to eliminate alloxanic acid as the parent compound of the radicals. The hyperfine structure is tentatively ascribed to the combined interaction of the odd electron with two equivalent ${ }^{14} \mathrm{~N}$ nuclei and two equivalent protons, assuming approximately equal hyperfine interaction fields of the nitrogen nuclei and the protons. The origin of the spectrum is schematically illustrated in Fig. 4. The interpretation suggested was supported by the result obtained when alloxan was reduced by glutathione 
Fig. 4. Schematic diagram of the splittings obtained by the interaction of the odd electron with one respectively two equivalent ${ }^{14} \mathrm{~N}$ nuclei, and with two equivalent ${ }^{14} \mathrm{~N}$ nuclei and two equivalent protons. The hyperfine interaction fields of the ${ }^{14} \mathrm{~N}$ nuclei and the protons are set equal. The numbers refer to the relative intensities of the absorp-

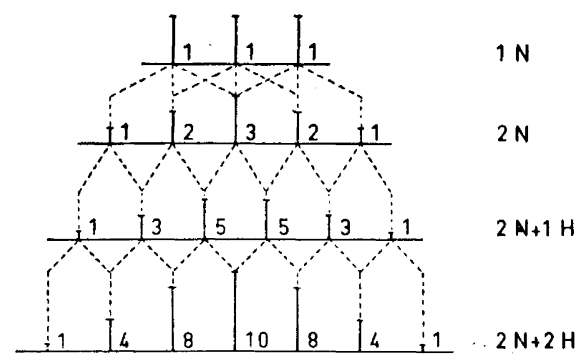

in a buffer solution prepared from heavy water. The appearance of a fiveline structure in place of the seven-line one indicates that the odd electron of the radicals produced in heavy water interacts with two equivalent ${ }^{14} \mathrm{~N}$ nuclei only, and that the two protons have been exchanged for deuterium nuclei which do not give rise to any hyperfine interaction under the prevailing conditions.

Alloxan may exist in two tautomeric forms (Fig. 5). Probably alloxan is present as a dihydrate in water solution. The radicals are believed to be derived from the keto form in which the hydrogen atoms are attached to the ring nitrogen atoms since experience from many free radical systems shows that hydroxyl protons do not give rise to any observable splittings in the ESRspectra due to a rapid exchange with solvent protons ${ }^{\text {? }}$.

Thus, the seven-line spectrum is suggested to be due to the combined interaction of the two equivalent nitrogen nuclei of the pyrimidine ring of alloxan and the two equivalent imino protons. Evidently the average time for the protons to be in an imino-position is long enough to give rise to a resolved structure.

Since free radicals are present in a solution of a relatively high alloxan concentration without any addition of reducing substances, it seems likely that free radicals are normal intermediates in the equilibrium system alloxandialuric acid. The addition of reducing substances to alloxan, or oxidizing<smiles>O=c1[nH]c(O)c(O)c(=O)[nH]1</smiles><smiles>Oc1nc(O)c(O)c(O)n1</smiles><smiles>O=C1N=C(O)N=C(O)C1(O)O</smiles><smiles>O=C1NC(=O)C(=O)C(=O)N1</smiles><smiles>O=C1N=C(O)N=C(O)C1=O</smiles>

DIALURIC ACID

ALLOXANTIN

Fig. 5. Structure formulas. The non-hydrate keto and enol forms of dialuric acid and alloxan are shown. 
substances to dialuric acid, obviously increases the concentration of free radicals.

It is evident that the alloxan radicals belong to a rather complex system in which several reactions take place: $(a)$ the irreversible conversion of alloxan to alloxanic acid, $(b)$ formation and decay of free radicals, $(c)$ formation and decay of dialuric acid and $(d)$ formation and decay of alloxantin. In view of all these reactions the data concerning the formation and decay of the alloxan radicals set out in sections $A$ to $D$ seem to be very incomplete. However, in order to make a more elaborate study of the kinetic behaviour of the alloxan radicals, it would be necessary to record the radical concentration continuously together with the concentrations of the other substances involved, including a recording of $\mathrm{pH}$-values.

At present it is unknown if the free radicals here described are of any significance for the toxic effects produced by alloxan on living tissues, nor is it known whether there is any relationship between the alloxan radicals and the substance with an optical absorption maximum at $305 \mathrm{~m} \mu$ reported $^{3}$ to be produced in the reaction between alloxan and glutathione in addition to dialuric acid.

Finally, it may be suggested that the alloxan radicals are involved in the formation of alloxantin.

Acknowledgement. The authors are indebted to Wilhelm och Martina Lundgrens Vetenskapsfond for financial support.

\section{REFERENCES}

1. Dunn, J. S., Shehan, H. L. and McLetchie, N. G. B. Lancet 244 (1943) 484.

2. Lazarow, A. Proc. Soc. Exptl. Biol. Med. 61 (1946) 441.

3. Patterson, J. W., Lazarow, A. and Levey, S. J. Biol. Chen. 177 (1949) 197.

4. Lazarow, A. Physiol. Rev. 29 (1949) 48.

5. Glasoe, P. G. and Long, F. A. J. Phys. Chem. 64 (1960) 188.

6. Seligson, D. and Seligson, H. J. Biol. Chem. 190 (1951) 647.

7. Ingram, D. J. E. Free Radicals as Studied by Electron Spin Resonance, Butterworths, London 1958, p. 174.

Received March 18, 1963. 